\title{
Maxwell's Equations of Electrodynamics An Explanation
}




\title{
Maxwell's Equations of Electrodynamics An Explanation
}

\author{
David W. Ball
}

\section{SPIE \\ PRESS}

Bellingham, Washington USA 
Library of Congress Cataloging-in-Publication Data

Ball, David W. (David Warren), 1962-

Maxwell's equations of electrodynamics : an explanation / David W. Ball. pages $\mathrm{cm}$

Includes bibliographical references and index.

ISBN 978-0-8194-9452-8

1. Maxwell equations. 2. Electromagnetic theory. I. Title.

QC670.B27 2012

530.14 ' $1-\mathrm{dc} 23$

2012040779

Published by

SPIE

P.O. Box 10

Bellingham, Washington 98227-0010 USA

Phone: +1360.676 .3290$

Fax: +1360.647 .1445$

Email: Books@spie.org

Web: http://spie.org

Copyright (C) 2012 Society of Photo-Optical Instrumentation Engineers (SPIE)

All rights reserved. No part of this publication may be reproduced or distributed in any form or by any means without written permission of the publisher.

The content of this book reflects the work and thoughts of the author(s).

Every effort has been made to publish reliable and accurate information herein, but the publisher is not responsible for the validity of the information or for any outcomes resulting from reliance thereon.

Printed in the United States of America.

First printing

\section{O SPIE}




\section{Dedication}

This book is dedicated to the following cadets whom I had the honor of teaching while serving as Distinguished Visiting Faculty at the US Air Force Academy in Colorado Springs, Colorado, during the 2011-12 academic year:

Jessica Abbott, Andrew Alderman, Bentley Alsup, Ryan Anderson, Austin Barnes, Daniel Barringer, Anthony Bizzaco, Erin Bleyl, Nicholas Boardman, Natasha Boozell, Matthew Bowersox, Patrick Boyle, Andrew Burns, Spencer Cavanagh, Kyle Cousino, Erin Crow, Michael Curran, Chad Demers, Nicholas Fitzgerald, Kyle Gartrell, James Gehring, Nicholas Gibson, Ahmed Groce, Kassie Gurnell, Deion Hardy, Trevor Haydel, Aaron Henrichs, Clayton Higginson, Anthony Hopf, Christopher Hu, Vania Hudson, Alexander Humphrey, Spencer Jacobson, Stephen Joiner, Fedor Kalinkin, Matthew Kelly, Ye Kim, Lauren Linscott, Patrick Lobo, Shaun Lovett, James Lydiard, Ryan Lynch, Aaron Macy, Dylan Mason, Ryan Mavity, Payden McBee, Blake Morgan, Andrew Munoz, Patrick Murphy, David Myers, Kathrina Orozco, Nathan Orrill, Anthony Paglialonga, Adam Pearson, Emerald Peoples, Esteban Perez, Charles Perkins, Hannah Peterson, Olivia Prosseda, Victoria Rathbone, Anthony Rosati, Sofia Schmidt, Craig Stan, James Stofel, Rachele Szall, Kevin Tanous, David Tyree, Joseph Uhle, Tatsuki Watts, Nathanael Webb, Max Wilkinson, Kamryn Williams, Samantha Wilson, Trevor Woodward, and Aaron Wurster.

May fortune favor them as they serve their country. 


\section{Contents}

Preface ix

Chapter 1 History................................................................... 1

$1.1 \quad$ History (Ancient) ........................................................................ 2

1.2 History (More Recent)..................................................................... 7

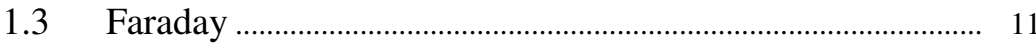

Chapter 2 First Equation of Electrodynamics ...................... 17

2.1 Enter Stage Left: Maxwell ..................................................... 17

2.2 A Calculus Primer......................................................................... 19

2.3 More Advanced Stuff................................................................. 26

$2.4 \quad$ A Better Way ............................................................................. 35

2.5 Maxwell's First Equation ........................................................ 40

Chapter 3 Second Equation of Electrodynamics .................. 47

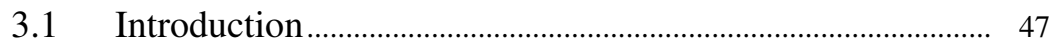

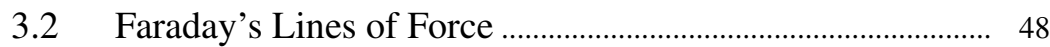

3.3 Maxwell's Second Equation ..................................................... 50

Chapter 4 Third Equation of Electrodynamics .......................... 55

4.1 Beginnings ................................................................................ 55

4.2 Work in an Electrostatic Field.................................................. 59

4.3 Introducing the Curl .............................................................. 67

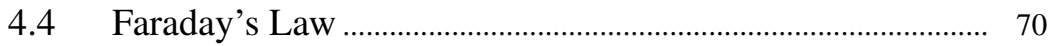

vii 
Chapter 5 Fourth Equation of Electrodynamics

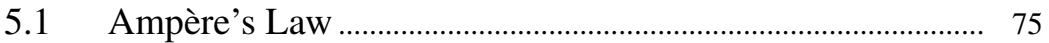

5.2 Maxwell's Displacement Current …………............................. 78

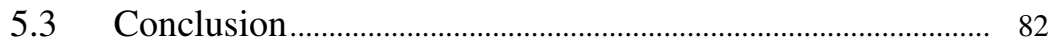

Afterword Whence Light? ................................................... 83

A.1 Recap: The Four Equations ………………………………..... 83

A.2 Whence Light? ....................................................................... 84

A.3 Concluding Remarks....................................................................... 87

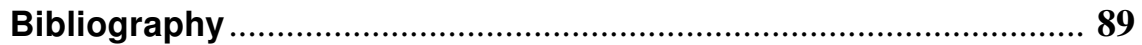

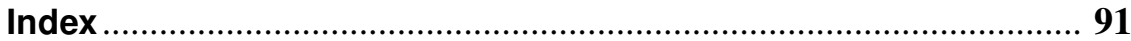




\section{Preface}

As the contributing editor of "The Baseline" column in Spectroscopy magazine, I get a lot of leeway from my editor regarding the topics I cover in the column. For example, I once did a column on clocks, only to end with the fact that atomic clocks, currently our most accurate, are based on spectroscopy. But most of my topics are more obviously related to the title of the publication.

In late 2010 or so, I had an idea to do a column on Maxwell's equations of electrodynamics, since our understanding of light is based on them. It did not take much research to realize that a discussion of Maxwell's equations was more than a 2000-word column could handle-indeed, whole books are written on them! (Insert premonitional music here.) What I proceeded to do was write about them in seven sequential installments over an almost two-year series of issues of the magazine. I've seldom had so much fun with, or learned so much from, one of my ideas for a column.

Not long into writing it (and after getting a better understanding of how long the series would be), I thought that the columns might be collected together, revised as needed, and published as a book. There is personal precedent for this: In the early 2000s, SPIE Press published a collection of my "Spectroscopy" columns in a book titled The Basics of Spectroscopy, which is still in print. So I contacted then-acquisitions-editor at SPIE Press, Tim Lamkins, with the idea of a book on Maxwell's equations. He responded in less than two hours... with a contract. (Note to budding authors: that's a good sign.)

Writing took a little longer than expected, what with having to split columns and a year-long professional sojourn to Colorado, but here it is. I hope the readers enjoy it. If, by any chance, you can think of a better way to explain Maxwell's equations, let me know-the hope is that this will be one of the premiere explanations of Maxwell's equations available.

Thanks to Tim Lamkins of SPIE Press for showing such faith in my idea, and for all the help in the process; also to his colleagues, 
Dara Burrows and Scott McNeill, who did a great job of converting manuscript to book. Thanks to the editor of Spectroscopy, Laura Bush, for letting me venture on such a long series of columns on a single topic. My gratitude goes to the College of Sciences and Health Professions, Cleveland State University (CSU), for granting me a leave of absence so I could spend a year at the US Air Force Academy, where much of the first draft was written, as well as to the staff in the Department of Chemistry, $\mathrm{CSU}$, for helping me manage certain unrelinquishable tasks while I was gone. Thanks to Bhimsen Shivamoggi and Yakov Soskind for reading over the manuscript and making some useful suggestions; any remaining errors are the responsibility of the author. Never-ending appreciation goes to my family-Gail, Stuart, and Casey-for supporting me in my professional activities. Finally, thanks to John Q. Buquoi of the US Air Force Academy, Department of Chemistry, for his enthusiastic support and encouragement throughout the writing process.

David W. Ball

Cleveland, Ohio

November 2012 